\title{
Diverse key nitrogen cycling genes nifH, nirS and nos $Z$ associated with mangrove rhizosphere soils of Pichavaram as revealed by culture dependent and independent analysis.
}

\section{Baskaran Viswanathan}

ICAR - Central Institute of Brackishwater Aquaculture

Prabavathy vaiyapuri ramalingam ( $\sim$ prabavathym@gmail.com )

M.S. Swaminathan Research Foundation https://orcid.org/0000-0002-8260-040X

\section{Research Article}

Keywords: PCR-DGGE, Nitrogen fixation, Denitrification, Gammaproteobacteria, BOX-PCR

Posted Date: April 7th, 2021

DOl: https://doi.org/10.21203/rs.3.rs-262569/v1

License: (a) (1) This work is licensed under a Creative Commons Attribution 4.0 International License. Read Full License 


\section{Abstract}

PCR-DGGE and culturable diversity analysis of nitrogenase gene nifH and denitrifying genes nirS and nosZ affiliated with heterotrophic and unculturable bacterial communities associated with rhizosphere of A. marina, $R$. mucronata, S. maritima and $S$. brachiata revealed the dominance of gammaproteobacterial community across the rhizospheres. Sequence analysis of the PCR-DGGE profiles of nifH genes clustered to unculturables, while majority of the nirS and nosZ genes clustered with unculturables with few culturable groups viz., Pseudomonas sp. and Halomonas sp. Culturable analysis reflected the dominance of Gammaproteobacteria as both nitrogen fixers and denitrifiers while other groups like Firmicutes and Alphaproteobacteria were very less represented among nitrogen fixers, and denitrifiers respectively. A total of 16 different genera were identified as nitrogen fixers and denitrifiers. BOX-PCR analysis of Mangovibacter, Vibrio, Bacillus and Catenococcus isolated in this study showed varied fingerprinting patterns compared to their respective positive controls reported earlier from this ecosystem, indicating they may be novel.

\section{Introduction}

Nitrogen is one of the most important nutrient in any ecosystem; the nitrogen cycle mediated by microbes is a very complex process which involves transformation of nitrogen to different forms through nitrogen fixation, nitrification, denitrification, ammonification, anaerobic ammonium oxidizing, and dissimilatory nitrate reduction to ammonium (Purvaja et al. 2008). Genomics research and high-throughput Illumina sequencing methods provide a broader prespective on the diverse microbial communities and their functional genes involved in the nitrogen cycling process (Zhang et al. 2017).

The mangrove ecosystems located between terrestrial and marine interface environments along the tropical and subtropical coastline are frequently inundated by floods and high tides (Holguin et al., 200; Giri et al. 2011), but play a major role in protecting the coasts in the tropical and subtropical regions. This ecosystem is partially anaerobic coupled with high salinity and oxido-reductive potential; the microbiota associated with mangroves is represented by a combination of terrestrial, freshwater and marine microorganisms that are crucial to the biogeochemical productivity (Vazquez et al. 2000). The bacterial and archaeal groups inhabiting this ecosystems play a major role in nutrient transformation, ecological and biogeochemical functions (Cao et al. 2011), and is influenced by salinity (Silveira, 2011), organic carbon (Dunaj et al. 2012), nitrogen content (Carriero et al. 2012), climate, and chemical substances (Bragazza, 2015), which in turn determine the diversity, distribution and function of the microbial communities in this ecosystem. The mangroves serve as a hot spot for the discovery of novel microbes with novel ecological functions (Rameshkumar et al. 2014; Raju et al. 2016).

Nitrogen fixation and denitrification have been reported in phylogenetically diverse group of bacteria and archaea; their diversity and distribution can be determined by targeting the functional marker genes such as nifH, nirS and nosZ (Jenkins and Zehr, 2008). Diverse group of bacteria and archaea harboring nifH/ nirS involved in nitrogen fixation and denitrification have been reported from the estuarine 
ecosystems. Since most of these remain unculturable, advanced molecular tools have been employed to understand the diversity, function and distribution of these microbial groups (Ren et al. 2018). Nitrogen fixation, a process where gaseous nitrogen $\left(\mathrm{N}_{2}\right)$ is converted to biologically available forms such as ammonia $\left(\mathrm{NH}_{3}\right)$ by diazotrophs is considered to be the major source of combined nitrogen input in mangrove forest habitats. Thus, the high productivity of mangrove ecosystems might be partially attributable to the high rate of biological nitrogen-fixing activity of free living diazotrophs in rhizosphere of mangroves as well as the sediments (Holguin et al. 2001).

Denitrification, a functional trait distributed among taxonomically diverse group of microbes, (Zhang et al. 2013) is primarily a bacterial respiratory process regulated by four different enzymatic steps and cataslysed by four mettaloproteins such as nitrate reductases, nitrite reductases (nir), nitric oxide reductase and nitrous oxide reductases (nos) (Braker et al. 2000). Denitirification is reported in a wide range of heterotrophic (e.g., Pseudomonas stutzeri, Pseudomonas aeruginosa, and Paracoccus denitrificans) and autotrophic bacterial communties (e.g., Thiobacillus denitrificans) belonging to the phylum proteobacteria (Green et al. 2010). However, the microbe mediated denitrification also acts as a sink by removing the excess anthropogenic $N$ input, thus preventing the transport of excess nitrogen to the estauarine and coastal systems which pose a serious threat to these ecosystems.

With the culture based analysis only a minimal proportion of the microbial population can be retrieved from any sample, leaving the rest undetected or uncultured. Hence, recent studies on microbial community assessment, using a wide range of techniques such as classical cultivation procedure, fingerprinting, clone libraries and next generation sequencing (Andreote, 2012; Zhang et al. 2017) have revealed the extensive microbial diversity and its function that were not detected earlier. DGGE is one of the fingerprinting approaches that have been designed to study microbial communities which cannot be achieved with the cultivable fraction represented by $>1 \%$ of the total number of prokaryotic species present in a given sample. DGGE has been used to exploit communities from a wide range of ecosystems and also the microbes that are involved in biogeochemical cycling of an ecosystem (Rastogi et al. 2010).

This study mainly focused on accessing the diversity and distribution of bacterial communities associated with mangrove rhizospheres that contribute to nitrogen fixation by targeting the $\mathrm{nifH}$ genes and the denitrifiers harbouring nirS and nos $Z$ gene by both culture dependent and independent approaches. Therefore exploring the diversity and distribution of rhizosphere associated diazotrophs and denitrifying microbial communities that drive the nitrogen cycle is essential to understand the biogeochemical cycling of nitrogen.

\section{Materials And Methods}

\section{Site description and sampling:}

The study site Pichavaram mangroves is located on the southeast coast of India near Chidambaram, situated about $250 \mathrm{~km}$ away from Chennai. It is an estuary located in between Coleroon and Velar estuary 
(GPS data) which covers a total area of 1350 ha colonized by true mangrove species and some halophytic plants. The rhizosphere soil samples of $A$. marina, $R$. mucoronata, S. maritima and $S$. brachiata were collected randomly using a soil core, and transferred to sterile polyethylene bags and transported to the laboratory on ice within $6 \mathrm{hrs}$. The geographical location of each sampling sites were recorded using a global positioning system instrument (GPS) (GARMIN Etrex, Taiwan). A total of 10 samples were collected from the rhizosphere region with a minimum distance range of $2 \mathrm{kms}$ of which 3 samples were from $A$. marina, 3 from $R$. mucronata, 2 from the intersecting region of $A$. marina and $R$. mucronata, 1 sample each from S. maritima and S. brachiata. The samples were stored at $-80{ }^{\circ} \mathrm{C}$ for deoxyribonucleic acid (DNA) extraction.

\section{Soil DNA extraction and PCR amplification of nitrogen cycling genes.}

Total genomic DNA was extracted from each rhizosphere soil sample by CTAB-SDS method as described by Ghosh et al. (2010) and purified using MO-BIO DNA (MO BIO Laboratories, USA) clean up kit as per manufacturers guidelines and stored at $-20^{\circ} \mathrm{C}$ for further analysis. The targeted genes were amplified using gene specific primers and annealing conditions are given in table 2 . Amplification was verified by agarose gel electrophoresis and was subjected to DGGE analysis.

\section{PCR-DGGE analysis}

About $45 \mu$ of the amplified products were loaded onto DGGE gel in Dcode ${ }^{\mathrm{TM}}$ mutation detection system (Bio-Rad, Laboratories, CA, USA). The electrophoresis was carried out at a constant temperature of $60^{\circ} \mathrm{C}$ for $17 \mathrm{hrs}$, in $8 \%$ polyacrylamide gel (100\% denaturant, $7 \mathrm{M}$ urea, and $40 \%$ (vol/vol) formamide) with a $50 \%$ to $60 \%$ denaturant gradient and stained with SYBR gold nucleic acid and kept in dark for 20 mins. The gel was then rinsed with double sterilized dist. water and the gel images were documented using UV illuminator (Gel-doc XR+, Bio-Rad laboratories, CA, USA). The digitized gel images were analysed using Bio-Rad fingerprinting II software and the position of the bands were recorded and the variable bands were then eluted from the gel by marking the band position with a sterile scalpel and transferred to sterile micro centrifuge tubes with TE buffer $(\mathrm{pH} 8.0)$ and incubated overnight at $4{ }^{\circ} \mathrm{C}$. To reconfirm the purity and position of the bands, $6 \mu$ of the eluted bands was used as a template, with the same combination of DGGE primers but without GC clamps, the total reaction volume was made upto $50 \mu \mathrm{l}$, reamplified and run in the same gradient DGGE and its position was confirmed and the products were purified.

\section{Cloning and sequencing of DGGE bands}

The purified PCR products were then ligated into pTZ57R/T cloning vector (InsTAclone PCR cloning kit, Fermentas, Thermo scientific) and the ligation mixture was prepared as per the manufacturers instruction with slight modification, which contained $1 \mu$ l of 10 X ligation buffer, $5 \mu$ l of template DNA, $1 \mu$ l of vector, 1 $\mu \mathrm{l}$ ligase enzyme and $2 \mu \mathrm{l}$ of nuclease free water. The mixture was then incubated at $4{ }^{\circ} \mathrm{C}$ overnight for efficient ligation and transformed into competent cells of E. Coli strain XL1-Blue (Novagen, Madison, WI, USA). Plasmids were extracted using the Favorgen plasmid DNA extraction Miniprep kit (Favrgen, Taiwan) as per manufacturer instruction and the positive clones were sequenced. All the sequences were 
analysed through BLAST-N for determining the taxonomic identity and tBLAST-X for determining the protein identity. Phylogenetic trees were constructed by neighbor joining method using Mega 5.0.

\section{Data analysis}

Digitized images of DGGE fingerprint were used to quantify diversity by using quantity one software which detects bands and quantifies the relative concentrations of amplified bands from cumulative pixel intensities within a given lane. The Shannon diversity index was calculated from the number of bands and relative intensities of bands present in each lane. In order to evaluate the correlation between the diversity of nifH, nirS and nosZ genes among the different rhizosphere regions, multivariate Principle Component Analysis (PCA) was performed from the data obtained from the DGGE patterns, based on band intensity and position, and were analyzed by adopting PCA. All the values were log transformed before subjecting to analysis and PCA was performed using PAST 3.0. The similarities between the DGGE profiles were displayed graphically as a dendrogram based on UPGMA algorithms (unweighted pair group method with arithmetic averages).

\section{Culturable analysis of nitrogen fixers and denitrifiers}

About $5 \mathrm{~g}$ of the individual rhizosphere soil samples were transferred into test tubes containing $50 \mathrm{ml}$ of sterile dist. water and vortexed for about $30 \mathrm{~min}$ and serially diluted upto $10^{8}$, about $0.1 \mathrm{ml}$ was spread plated onto LB agar, Nitrogen free medium and BTB agar plates. The plates were incubated for 3-4 days at room temperature and based on colony morphology, individual colonies were picked, and maintained as pure cultures in their respective media and also stored in $25 \%$ glycerol stocks at $-80{ }^{\circ} \mathrm{C}$.

\section{Genomic DNA isolation of culturable bacteria}

Genomic DNA was extracted from overnight grown cultures in $10 \mathrm{ml} \mathrm{LB}$ broth incubated at $32^{\circ} \mathrm{C}$ for 24 hrs. The isolated DNA were subjected to PCR based screening for the presence of nitrogen fixers and denitrifiers (Table 2).

\section{Screening for nifH, nirS and nosZ harboring bacteria:}

The nifH gene fragments were amplified using primers as described by Poly et al. (2001) and the denitrifiers, nirS and nos $Z$ gene were amplified using primers described by Braker et al. (2000). All the PCR reactions were carried out in BioRad T100 thermal cycler. Primers and PCR conditions are given in table

\section{Genetic diversity analysis using BOX PCR fingerprinting}

The genetic diversity among nitrogen fixing and denitrifiers was determined by BOX-PCR profiling using BOX A1R primers (BenHaim et al. 2003). Primer and amplification conditions are given in the table (2). About $5 \mu \mathrm{l}$ of the PCR products were run in $\mathrm{EtBr}$ stained $2 \%$ agarose gel in $0.5 \mathrm{X}$ TBE buffer at a constant voltage of $80 \mathrm{~V}$ for 3-4 hours. The BOX-PCR profiles were visualized under UV illuminator, followed by 
digital image capturing using BioRad gel documentation system. Normalization, recognition and band assignment were made using Fingerprinting II software (BioRad, USA) by Dice coefficient with optimum range of $0.5 \%$. The cluster analysis of similarity matrices was performed by Unweighted Pair Group with Mathematical Average (UPGMA) for dendrogram analysis.

\section{Sequencing and Data Analysis of culturable bacteria}

The universal bacterial primers $27 \mathrm{f}$ and $1492 \mathrm{r}$ were used to amplify culturable bacterial $16 \mathrm{~S}$ rDNA genes and sequenced byEurofins India Pvt. Itd. The sequence similarities were compared in EzTaxon databases (Chun, 2007). The phylogenetic trees were constructed, using MEGA 5.0 (Tamura, 2011) to determine the taxonomic affiliation.

\section{Nucleotide sequence and accession numbers}

The sequences data obtained in this study were deposited in NCBI genebank under the following accession number- Culturable nitrogen fixers 16S rDNA: KU131229-131270, and denitrifiers 16S rDNA KU131271-131297. Unculturable nifH, nirS and nosZ: KY204253- 204281, KY204282-204312, KY204313204333.

\section{Results And Discussion}

\section{Soil characteristics}

The physico-chemical properties of the rhizosphere soils of Pichavaram are shown in table 1. The soil pH was 7.2 , the organic carbon $(\mathrm{OC})$ was $<0.78 \%$ and the organic matter $1.34 \%$. The total nitrogen content was $916 \mathrm{mg} / \mathrm{kg}$ while available nitrogen was low with $173 \mathrm{mg} / \mathrm{kg}$. Available Phosphorus as P, zinc as Z, copper as $\mathrm{Cu}$, manganese as $\mathrm{Mn}$, molybdenum as $\mathrm{Mo}$ and boron as $\mathrm{B}$ were found to be below detection limit (BDL). It was found that the available potassium as $\mathrm{K}$ was the most abundant macronutrient (980 $\mathrm{mg} / \mathrm{kg}$ ) in Pichavaram soil (Table 1).

\section{Culturable bacteria from mangroves}

A total of 579 culturable bacterial isolates with different colony morphology were selected and screened for nitrogen fixers and denitrifiers. All the isolates were maintained in LB agar for further analysis and stored as glycerol stock in $-80 \bowtie \mathrm{C}$.

\section{Culture independent analysis of nifH gene diveristy (PCR-DGGE)}

The DGGE profiles of nifH genes of all the 5 rhizosphere samples showed varied banding pattern with a total of 10-15 bands per lane (Fig. 1). The profiles represented rich diversity in all the rhizosphere samples except $S$. maritima rhizosphere which had only 3-5 bands,indicating a low level of diversity of nifH gene associated with this rhizosphere. A total of 29 DGGE ribotypes for nifH (Fig. 1) were eluted and assigned a unique number with a prefix MSSRF ie MSSRF $1 \mathrm{H}$ to MSSRF $29 \mathrm{H}$. 


\section{Cluster analysis of nifHDGGE ribotypes}

The DGGE ribotypes of nifH gene formed three major clusters (i) cluster A represented $n$ ifH ribotypes of $A$. marina, S. maritima and $R$. mucronata rhizosphere (ii) cluster B represented nifH ribotypes of $A$. marina and $R$. mucronata rhizospheres, their intersecting region and S. brachiata rhizosphere (iii) cluster $\mathrm{C}$ represented nifH ribotypes of $R$. mucronata and intersecting region of both $A$. marina and $R$. mucronata at $60 \%$ confidence level with considerable variation observed among different rhizosphere samples (Fig. 1b.)

\section{Phylogenies of nifH gene sequences}

The nifH genes have been used as marker genes for studying the nitrogen fixing bacterial diversity and a number of bacterial groups harboring nifH genes have been reported in mangrove sediments, revealing high diazotrophic diversity in mangrove ecosystems (Zhang, 2008; 2017). The taxonomic identification of nitrogen fixing bacterium that represents the unique DGGE bands are summarized in the table (S1). BLAST-N analysis of 29 sequences revealed that 10 sequences fell in the range of $80-89 \%$ similarity values and 19 sequences fell within the range of $90-99 \%$ and were similar to $\mathrm{nifH}$ gene of uncultured organisms reported from various ecosystems. However, protein analysis revealed that majority of the sequences fell between $94-100 \%$ with similarity to the known nifH sequences of various environmental origins especially from saline soil and marine sediments. This indicates that the mangrove rhizosphere region harbors nitrogen fixing bacterial communities similar to saline and marine environments. Further phylogenetic analysis of nifH gene formed two major clusters with 11 subclusters indicating the presence of diverse nifH gene in this ecosystem. All the sequences in cluster 1 represented the sequences from marine sediments, saltmarsh, high and low saline soils and sea sediments while cluster 2 showed similarity to sequences from rhizosphere soil of paddy and other terrestrial ecosystem (Fig. S1).

Previous reports suggested that phylum Proteobacteria particularly Gammaproteobacteria and Deltaproteobacteria are the predominant $\mathrm{nifH}$ genes harbouring groups in the rhizosphere sediments from many mangrove species, (Wu et al. 2016; Zhang et al. 2017), similarly in the present study also Proteobacteria were found to harbor nifH genes-predominantly, which may be contributing to nitrogen fixation in the mangrove ecosystem. In addition to proteobacterial groups, Firmicutes were also found to harbor nifH genes, Similarly, nifH gene sequences affiliated with alpha, beta and gamma proteobacteria, have been reported previously by Bagwell et al. (2002), from the tropical seabed grass which is in concurrence with our study. The findings of Bird et al. (2005) suggested that gamma proteobacteria are predominant and acts as an important component of the heterotrophic nitrogen fixing microbial community of the tropical and subtropical oceans. The sequence analysis of nifHDGGE showed similarity to uncultured nitrogen fixing bacterial groups reported from high and low saline soils (Yousuf, 2014), marine sediments (Dang, 2013), rhizosphere of smooth cordgrass and salt marsh (Lovell, 2012), and agricultural soils (Pereira, 2013). None of the 29 nifH sequences reported in this study were related to earlier known nifH genes of cultured nitrogen-fixing bacteria reported neither from mangroves nor from other ecosystems, indicating the abundance of unreported uncultured nitrogen-fixing bacteria in the 
mangrove rhizosphere soils. The phylogenetic placement of the nifH gene sequences from the mangroves exhibited unique nifH gene types affiliated with the phyla belonging to unculturables. The sequences were partially matching with the nitrogen fixers described from marine environments, and also those found in other ecosystems. Thus, the distribution of the nifH gene in the mangrove ecosystems represented both the marine and the terrestrial ecosystems.

\section{Diversity of culturable nitrogen fixing bacteria}

Nearly 52 strains formed pellicle in nitrogen free medium and showed positive amplification for $n$ ifH gene with amplicon size of 360 bp compared to Ciceribacter lividus MSSRFBL $1^{\top}$ used as positive control. The BOX-PCR fingerprinting of the 52 strains showed genetic variation and formed 23 clusters at $80 \%$ confidence level (Fig. 2a). BOX-PCR based analysis has been widely recognized as one of the most common tools for determining the microbial diversity particularly between closely related groups (Ikeda, 2013).

Our current knowledge on the microbial community pertaining to the South Indian mangrove ecosystems, is still largely based on cultivation-dependent studies (Rameshkumar, 2014; Viswanath et al. 2015; Raju et al. 2016;). This needs to be further expanded using current molecular tools to completely understand the diversity of the nitrogen fixers associated with this ecosystem.

\section{Taxonomic classification of bacterial isolates harboring nifH gene}

PCR based 16S rRNA amplification and sequencing analysis of 1350-1410 bp of the amplified product of the culturable nitrogen fixers assigned the taxonomic identification upto generic and species level. The EzTaxon analysis of 16S rRNA gene sequences of the positive strains were compared with available sequences of the type strains in the database and were assigned the respective taxonomic position. The positive nitrogen fixers predominantly belonged to Gammaproteobacteria particularly the genus Vibrio (31\%) comprising of seven species ie., $V$. plantisponsor MSSRF $40^{\top}, V$. alginolyticus NBRC $15630^{\top}, V$. azureus NBRC $104587^{\top}$, V. diabolicus $\mathrm{HE} 800^{\top}$, V. natrigenes DSM $759^{\top}$, V. parahemolyticus NBRC $12711^{\top}$, and $V$. neocaledonicus $\mathrm{NC}^{-170^{\top}}$; followed by Mangrovibacter (12\%) belonging to $M$. plantisponsor MSSRF $40^{\top}$, Klebsiella (12\%) comprising of K. pneumoniae (DSM 30104 ${ }^{\top}$ ), Serratia (6\%) belonging to $S$. marcescens $\left(\mathrm{KRED}^{\top}\right)$, and Catenococcus thiocycli DSM $9165^{\top}$; the Alphaproteobacteria group was represented by Rhodobacter johrii JA192 ${ }^{\top}$ (2\%), Azospirillum lipoferum $\mathrm{NCIMB} 18161^{\top}$ (2\%) (8\%) (Fig. $2 \mathrm{~b})$. The second largest phylum was Firmicutes represented by Bacillus (21\%) comprising of four species such as $B$. aerophilus $28 \mathrm{~K}^{\top}, B$. oceanisediminis $\mathrm{H}^{\top}{ }^{\top}, B$. subterraneus $\mathrm{DSM} 13966^{\top}$ and $B$. boroniphilus JCM 21738'; Staphylococcus (8\%) comprising of S. epidermis $\left(\right.$ ATCC14990 $^{\top}$ ).

Previous studies by Liu et al. (2012) showed that $55.6 \%$ of the nitrogen fixing bacterial community belonged to gammaproteobacteria, which substantiates the present results depicting the dominance of this microbial group in mangrove ecosystems. The results obtained in our study showed that majority of the culturable nitrogen fixers from the Pichavaram mangroves belonged to Gammaproteobacterial group 
coinciding with earlier reports (Rameshkumar 2014, 2010; Viswanath et al. 2015). Flores-Mireles et al. (2007) showed that the nitrogen fixers isolated from the rhizosphere of mangroves were distributed to various genera such as Azospirillum, Azotobacter, Rhizobium, Clostridium, Klebsiella, Vibrio, Phyllobacterium, Oceanimonas, Paracoccus, Corynebacterium, Arthrobacter, Aeromonas, and Pseudomonas, while this study also reported similar groups in addition Mangrovibacter and Rhodobactersp. were reported.The BOX-PCR profiling of vibrio consisiting of $V$. plantisponsor, $V$. alginolyticus and $V$. neocledonicus (Fig. 3a) was supported by the phylogenetic analysis of these strains as they formed an outward clade with the type strains. From Ez-Taxon analysis, it is understood that the isolates of species $V$. alginolyticus and $V$. neoclaedonicus cannot be distinguished based on 16S rDNA analysis and the difference in BOX profile of these strains suggest that these may be novel species. On a similar note, so far only two Mangrovibacter species has been reported (Rameshkumar, 2010; Zhang, 2015) from the mangroves but isolation of additional five Mangrovibacter species in this study displayed divergence from the reported strains in BOX-PCR profiling as well as phylogenetic analysis indicating they could possibly be novel species. The genus Bacillus obtained in this study, showed similarity to $B$. aerophilus $28 \mathrm{~K}^{\top}$ which has been previously reported in stratosphere region of earth's atmosphere by Shivaji et al. (2006). It is known that the strains B. aerophilus, B. startosphericus and B. altitudinis, (Fig. 3a) cannot be differentiated by $16 \mathrm{~S}$ rDNA analysis which is also well supported by BOX-PCR fingerprinting analysis. Our results confided the same thus suggesting that further experiments has to be donet in order to prove that these might be novel species exhibiting diazotrophic activity.

\section{Culture dependent and independent analysis of denitrifying bacteria}

\section{DGGE analysis of nirS and nos $Z$ genes}

Culture-independent approaches have been adopted to analyze the diversity of denitrifying genes like nirK, nirS and nosZ (Li et al. 2020; Gao, 2016) from forest and marine sediments. In this study nirS and nos $Z$ genes were used as molecular marker to determine the distribution and diversity of culturable and unculturable denitrifying populations of mangrove rhizosphere. A total of 31 DGGE ribotypes for cdnirS coding nitrite reductase (Fig. 3a) and 21 DGGE ribotypes for nosZ gene coding nitrous oxide reductase gene (Fig.4a) were eluted and assigned a unique number from MSSRF CD1 to MSSRF CD31 for cdnirS gene and MSSRF Z1 to MSSRF Z21 for nosZ gene.

\section{Cluster analysis of cdnirS and nosZ gene ribotypes}

At $60 \%$ confidence level, both nirS (Fig. 3b) and nosZ (Fig. 4b) genes formed five and four major clusters respectively, with a high degree of variation among the rhizosphere regions. The cluster A represented nirS genes from $A$. marina, $R$. mucronata and $S$. maritime rhizosphere, while cluster $B$ represents nirS genes from $A$. marina and $R$. mucronata, whereas cluster $\mathrm{C}, \mathrm{D}$ and $\mathrm{E}$ comprised ribotypes of intersecting region and $S$. brachiata. But the cluster analysis of nos $Z$ gene exhibited a unique pattern with the individual rhizosphere region forming single cluster, eg., cluster $\mathrm{A}$ comprised of nosZ ribotypes from A. marina and 
its intersecting region, cluster B represented nosZ ribotypes of $R$. mucronata, with outward cluster of samples from both $S$. maritima and $S$. brachiata.

\section{Phylogenies of nirS and nos $Z$ gene sequences}

The unique nirS sequences recovered from mangrove rhizosphere shared 94-100\% identities with known GeneBank sequences. After translation, the corresponding protein sequences shared $75-100 \%$ identities to the closest matched nirS sequences detected from variety of marine environments including estuarine sediments of pearl river estuary (cd13, cd30), Hai river (cd9, cd17,cd21), Yangtze river (cd4, cd10), Baltic sea sediments (cd6, cd15), lake sediments (cd20), South and East china sea (cd27, cd29), Salt marsh sediment (cd19, cd23), Solar saltern (cd25), sludge (cd7, cd8), Agriculture soil (cd26), coastal sediments (cd2, cd5, cd11, cd22), sediments (cd14, cd18), estuary (cd12, cd16), soil (cd24, cd31) and Landfill bioreactor respectively ( $c d 1, c d 3, c d 28)$, all which showed similarity to uncultured nitrite reductase coding genes. However, majority of the nirS (28 bands) sequences didn't match with culturable denitrifiers and showed similarity to uncultured nirS gene sequences. Only 3 bands namely CD29 showed $90 \%$ similarity to nitrite reductase gene of Pseudomonas, and two other bands CD25 and CD31 showed $96 \%$ and $92 \%$ similarity to nitrite reductase gene of Halomonas nitroreducens LMG $24185^{\top}$ and Halomonas cernia LMG $24145^{\top}$ strains respectively (Fig. S2 and table S2).

The nos $Z$ gene, encoding $\mathrm{N}_{2} \mathrm{O}$ reductase, an enzyme catalyzing the final step of denitrification, is largely unique to denitrifying bacteria. It represents the process leading to the loss of biologically available $\mathrm{N}$ from the sediments and has been used as a marker gene for determining the diversity of denitrifiers (Hong, 2019). The DGGE ribotypes of the nitrous oxide reductase gene (nosZ) showed rich diversity associated with $A$. marina rhizosphere. Nearly 21 prominent bands with 10-12 bands in each lane was eluted and sequenced. BLAST-N analysis of the nos $Z$ gene and the protein derived sequences showed 85$99 \%$ similarity and $83-98 \%$ similarities to unculturable nos $Z$ gene respectively. Nearly 18 sequences showed similarity to uncultured nitrous oxide reductase gene reported from various environmental sources while sequences of two bands MSSRF Z10 and MSSRF Z18 were present in all the rhizosphere samples and showed 95- 98\% similarity to Pseudomonas balearica DSM $6083^{\top}$ genome and band MSSRF Z17 from S. maritima rhizosphere showed 99\% similarity to $H$. nitroreducens LMG $24185^{\top}$ nitrous oxide reductase gene which was also confirmed by protein derived sequences. which shared $75-100 \%$ identities to the closest matched nosZ sequences detected from variety of marine environments including ocean sediments, sea sediments, salt marsh, fresh water, paddy soil, sewage water, solar saltern, laizhou bay soil, rhizosphere soil, Puccinia distans soil, agricultural and wheat soil. Phylogenetic analysis of protein derived sequences showed six clusters forming monophyletic clade with different known environmental sequences (Fig. S3 \& Table S3)..

The nirS (cd3afGC and R3Cd) and nosZ (nosZfGC and nosZ1773R) primer pair showed efficient amplification of the nirS and nos $Z$ genes from the denitrifying populations of the four different mangrove rhizospheres. Studies by Lee et al. (2017) and Xie et al. (2020) showed the abundance of denitryfing bacterial communities in pearl river estuary and sanfransisco bay were correlated with the present study. 
As reported in other environmental studies of the functional genes in the denitrification pathway, most of the dominant nirS and nosZ types in our study clustered with other environmental clones. Majority of the sequences belong to uncultured denitrifying bacterial group reported from various environmental sources such as land fill leachate, estuarine sediments, activated sludge, salt marsh, forest soil (Bárta et al. 2010; Zheng et al. 2015) as well as sludge and agricultural ecosystem (Yoshida, 2012; Zhang et al. 2013), suggesting that mangroves harbor denitrifying bacterial communities from both tidal and urban ecosystems. The results showed that majority of the nirS and nosZ gene obtained through DGGE analysis belonged to uncultured denitrifying bacterial group. Phylogenetic analysis of both nirS and nos $Z$ genes formed two different clusters with ocean, marine and estuarine sediments in one cluster and agricultural isolates in another cluster which indicates the wide distribution and yet to explore unknown bacterial lineages in this ecosystem.

\section{Diversity of culturable denitrifying bacteria}

About 112 strains grew in nitrate broth, of which 83 strains were selected based on nitrate/nitrite reduction and identified as true denitrifiers using Greiss reagent (data not shown). All these strains were screened for nitrite reductase and nitrous oxide reductase genes as described in materials and methods. Among the 83 cdnirS positive isolates only 74 isolates harbored nos $Z$ gene with the amplicon size of 1100 bp compared to Marinobacter hydrocarbanoclasticus SP17 ${ }^{\top}$ and thus indicating the presence of both nirS and nos $Z$ genes in 74 isolates while 9 isolates contained only nirS gene. The genetic diversity among these 83 strains analyzed by BOX-PCR fingerprinting showed the presence of 24 clusters at $80 \%$ confidence level (Fig. 5a).

\section{Taxonomy of denitrifying bacterial isolates}

Denitrification is well recognized as a dominant pathway for the removal of reactive nitrogen in an ecosystem. A number of studies upto date have reported denitrifier communities from marine habitats but only from distinct geographic locations (Arce, 2013; Alcantara, 2014).. Of these, $96 \%$ of cultured denitrifiers belonged to the gammaproteobacteria (Braker, 2000), most of them were the well-known genus Pseudomonas. BLAST-N analysis of the 16S rDNA of nitrate reducing bacterial groups revealed the predominant presence of genus Nitratireductor aquimarinus $\mathrm{VL}-\mathrm{SC} 21^{\top}(2)$, Staphylococcus hominis DSM $20328^{\top}(1)$ and Bacillus aryabhattai B8W22 ${ }^{\top}(2)$. BLAST-N analysis of denitrifiers were mostly represented by groups such as Pseudomonas sp. (48 isolates) comprising of $P$. bauzanensis DSM $22558^{T}, P$. xanthomarina KMM1447 ${ }^{\top}$, P. baleriaca DSM $6083^{\top}$, P. stutzeri ATCC $17588^{\top}$ and $P$. xiamenensis $\mathrm{C} 10-2^{\top}$, Paracoccus kondratievae GB ${ }^{\top}$ sp. (4 isolates), Labrenzia aggregata IAM $12614^{\top} \mathrm{sp}$. (5 isolates), Halomonas venusta DSM $4743^{\top}$ and $H$. hydrothermalis Slthf $2^{\top}$ (13 isolates), Virgibacillus dokdonensis DSW- $10^{\top}$ (4 isolates) and Shewanella marisflavi SW $117^{\top}$ (3 isolates) (Fig. 5b). The exploration of the culturable diversity of these nirS and nosZ in culturable heterotrophic bacterial isolates indicated the prominent distribution of these genes in the Gammaproteobacteria group (Qaisrani et al. 2019). The results obtained were on par with the previous studies on marine sediments (Bowman, 2005; Zhou 2009), which revealed that Gammaproteobacteria was the most abundant denitrifying population in mangroves. 
Studies by Fernandes et al. (2012) also showed the dominance of gammaproteobacteria in culturable and non-culturable denitrifiers from Tuvem and Divar estuary. Our results also were concurrent to earlier reports with predominant denitrifying community belonging to Gammaproteobacteria consisting of Pseudomonas and Halomonas groups as predominant denitrifiers.

In this study we were able to successfully screen and characterize some of the aerobic culturable heterotrophic denitrifying bacterial population from this ecosystem. In culturable analysis of denitrifiers, it was observed that majority of the isolates were from Gammaproteobacterial group which belonged to the genus Pseudomonas sp. Different group of bacterial genera like Halomonas, Labrenzia, Paracoccus, Nitratireductor, Bacillus, Virgibacillus, Shewanella, Staphylococcus were also observed to contribute to denitrifying activity. Previous known reports have shown that these microbial groups have been described from different ecosystems ie., Halomonas from hydrothermal vent (Kaye et al. 2011), Labrenzia from marine ecocystem as well as from halophytic plant Sueada (Bibi et al. 2014:) which were similar to the findings in this study. Other groups like Paracoccus (Flores mirles, 2007), Nitratireductor (Labbe, 2004), and Virgibacillus (Yoshida, 2012) were reported from marine as well as mangrove ecosystems except Bacillus which has been reported from the stratosphere (Shivaji, 2006). It was observed that the genus Pseudomonas, Labrenzia, Halomonas, Paracoccus, Virgibacillus and Shewanella were found to harbor both nirS and nosZ gene whereas other genera like Bacillus, Staphylococcus and Nitratireductor harbored only nirS gene. The denitrifying Pseudomonas comprised diversified species such as $P$. balearica, $P$. bauzanensis, $P$. xiamanensis, $P$. stutzeri and $P$. xanthomarina. This is the first study to describe the presence of $P$. balearica, $P$. bauzanensis, Labrenzia sp. and Paracoccus kondratievae from mangrove ecosystem and were found to be vigorous denitrifiers as they can convert nitrate into gaseous form of nitrogen within 24 hrs of incubation under aerobic conditions.

A strong correlation between the DGGE profiles of denitrifiers and culturable denitrifiers was observed. Some of the sequences of nirS showed similarity to P. balearica and nos $Z$ gene to Halomonas nitroreducens which has been observed in culture dependent studies as well. The study revealed that $80 \%$ of the denitrifiers belonged to Pseudomonas sp. and Halomonas sp. represented 16\% indicating the dominance of these two species in the rhizosphere contributing to denitrification.

Overall, the results obtained in this study coincides with the previous studies of marine sediments which showed Gammaproteobacteria as the most abundant nitrogen fixing and denitrifying population.

\section{Principal component anaylsis of DGGE fingerprints}

Principal component analysis of all the three genes nifH, NirS and NosZ showed the qualitative differences in the distribution of genes among the rhizosphere regions. The PCA analysis clearly separated the microbial communities into three different groups, well supported by UPGMA clustering analysis which showed that the distribution of these genes in halophytic plants is unique when compared to mangrove plants. All the mangrove rhizosphere formed unqiue clustering pattern as is revealed in PCA analysis (Fig. S4a), Both the mangrove rhizospheres A. marina and $R$. mucronata exhibited almost similar 
gene distribution profiles and formed a unique clustering pattern. Individual DGGE profile cluster analysis of these genes well corroborated with the PCA analysis and UPGMA analysis (Fig. S4b).

\section{Conclusion}

This is a basic study in an attempt to explore the diversity of culturable and unculturable microbial group involved in nitrogen fixation and denitrification process. To our knowledge this is the first paper attempting to explore the microbial communities involved in nitrogen fixation and denitrification process through culture depdendent and indepdenent analysis from Pichavaram mangroves. The results presented here provide baseline data about nitrogen fixing and denitrifying bacterial groups present in mangrove rhizosphere regions at the genetic level. It is essential to mention that two strains from Rhodobacteraceae family namely Rhodobacter johrii and Labrenzia aggregata involved in nitrogen fixation and denitrification process; sulfur cycling bacteria Catenococcus thiocycli involved in nitrogen fixation and nitrate reducing bacteria Nitratireductor are being reported for the first time from the mangrove ecosystem. Few novel groups belonging to Vibrio, Mangrovibacter, Catenococcus and Bacillus were identified based on BOX-PCR fingerprinting analysis. DGGE analysis revelaed the presence of many uncultured bacterial groups harboring genes involvd in nitrogen fixation and denitrification process. Overall, PCR- DGGE in combination with culture dependent studies revealed known as well as unknown microbial groups involved in nitrogen cycling process in this study. Further research has to be carried out to understand the expression of these genes under different conditions which will give a complete data on the microbial communities involved in this process.

\section{Declarations}

Funding The authors did not receive support from any organization for the submitted work.

Availability of data and material- The datasets generated during and/or analysed during the current study are available in the

Code availability-Not applicabale

\section{Acknowldegement}

This work was supported by Department of Biotechnology, Govt of India.

Author contributions. BV: Experiment designing, data analysis and writing. VRP: Supervision and crtical correction of the manuscript.

\section{Compliance with ethical standards}

Conflict of interest: The author's declare that they have no conflict of interest.

Research involving Human Participants and/or Animals: The study is not related to animals or humans. 


\section{References}

\section{References.}

1. Andreote FD, Jiménez DJ, Chaves D, Dias ACF, Luvizotto DM, Dini-Andreote F, Fasanella CC, Lopez MV, Baena S, Taketani RG et al (2012) The microbiome of Brazilian mangrove sediments as revealed by metagenomics. PLoS One 7:e38600

2. Arce MI, Gómez R, Suárez ML, Vidal-Abarca MR (2013) Denitrification rates and controlling factors in two agriculturally influenced temporary Mediterranean saline streams. Hydrobiologia 700:169-185

3. Bagwell C, Rocque J, Smith G, Polson S, Friez M, Longshore J, Lovell C (2002) Molecular diversity of diazotrophs in oligotrophictropical seagrass bed communities. FEMS microbiol. Ecol 39:113-119

4. Bárta Jř, Melichová T, Vaněk D, Picek T, Šantrůčková H (2010) Effect of pH and dissolved organic matter on the abundance of nirK and nirS denitrifiers in spruce forest soil. Biogeochemistry 101:123132. https://doi.org/10.1007/s10533-010-9430-9

5. Ben Haim Y, Thompson FL, Thompson CC, Cnockaert MC, Hoste B, Swings J, Rosenberg E (2003) Vibrio coralliilyticus sp. nov., a temperature-dependent pathogen of the coral Pocillopora damicornis. Int J Syst Evol Microbiol 53:309-315

6. Bibi F, Jeong JH, Chung EJ, Jeon CO, Chung YR (2014) Labrenzia suaedae sp. nov., a marine bacterium isolated from a halophyte, and emended description of the genus Labrenzia. Int J Syst Evol Microbiol. 2014 Apr;64(Pt 4):1116-1122. doi: 10.1099/ijs.0.052860-0. Epub Jan 9. PMID: 24408521

7. Bird C, Martinez Martinez J, O'Donnell AG, Wyman M (2005) Spatial distribution and transcriptional activity of an uncultured clade of planktonic diazotrophic y-proteobacteria in the Arabian Sea. Appl Environ Microbiol 71:2079-2085

8. Bowman JP, McCammon SA, Dann AL (2005) Biogeographic and quantitative analyses of abundant uncultivated gamma-proteobacterial clades from marine sediment. Microbial Ecol 49:451-460

9. Bragazza L, Bardgett RD, Mitchell EA, Buttler A (2015) Linking soil microbial communities to vascular plant abundance along a climate gradient. New Phytol 205:1175-1182

10. Braker G, Zhou J, Wu L, Devol AH, Tiedje JM (2000) Nitrite reductase genes (nirK and nirS) as functional markers to investigate diversity of denitrifying bacteria in pacific northwest marine sediment communities. Appl Environ Microbiol 66:2096-2104

11. Cao HL, Li M, Hong YG, Gu JD (2011) Diversity and abundance of ammonia oxidizing archaea and bacteria in polluted mangrove sediment. Syst Appl Microbiol 34:513-523

12. Carreiro-Silva M, Kiene WE, Golubic S, McClanahan TR (2012) Phosphorus and nitrogen effects on microbial euendolithic communities and their bioerosion rates. Mar Pollut Bull http:// dx.doi.org/10.1016/j.marpolbul.2011.12.013

13. Chun J, Lee JH, Jung Y, Kim M, Kim S, Kim BK, Lim YW (2007 EzTaxon) A web-based tool for the identification of prokaryotes based on 16S ribosomal RNA gene sequences. International Journal of Systematic and Evolutionary Microbiology. 57:2259-2261 
14. Dang HY, Yang JY, Li J, Luan XW, Zhang YB, Gu GZ, Xue RR, Zong MY, Klotz MG (2013) Environmentdependent distribution of the sediment nifH-harboring microbiota in the northern South China Sea. Appl Environ Microbiol 79:121-132 n ).

15. Dunaj SJ, Vallino JJ, Hines ME, Gay M, Kobyljanec C, Rooney-Varga JN (2012) Relationships between soil organic matter, nutrients, bacterial community structure, and the performance of microbial fuel cells. Environ Sci Technol 46(3):1914-1922

16. Fernandes SO, Michotey VD, Guasco S, Bonin PC, LokaBharathi PA (2012) Denitrification prevails over anammox in tropical mangrove sediments (Goa, India). Mar Environ Res 74:9-19

17. Ferreira TO et al (2010) Spatial patterns of soil attributes and components in a mangrove system in Southeast Brazil (São Paulo). J Soil Sediment 10:995e1006

18. Flores-Mireles AL, Stephen C, Winans, Gina Holguin1- (2007) Molecular Characterization of Diazotrophic and Denitrifying Bacteria Associated with Mangrove Roots- Appl Environ Microbiol 73:7308-7321

19. Gao J, Hou LJ, Zheng YL, Liu M, Yin GY, Li XF et al (2016) nirS-Encoding denitrifier community composition, distribution, and abundance along the coastal wetlands of China. Applied Environmental Microbiology 100:8573-8582. https://doi.org/10.1007/s00253-016-7659-5

20. Ghosh A, Dey N, Bera A (2010) Culture independent molecular analysis of bacterial communities in the mangrove sediment of Sundarbans, India. Saline Syst. 6(1)

21. Giri C, Ochieng E, Tieszen LL, Zhu Z, Singh A, Loveland T, Masek J, Duke N (2011) Status and distribution of mangrove forests of the world using earth observation satellite data. Glob Ecol Biogeogr 20:154-159

22. Green SJ, Prakash O, Gihring TM, Akob DM, Jasrotia P, Jardine PM, Watson DB, Brown SD, Palumbo AV, Kostka JE (2010) Denitrifying bacteria isolated from terrestrial subsurface sediments exposed to mixed-waste contamination. Appl Environ Microbiol 76:3244-3254

23. Holguin G, Vazquez P, Bashan Y (2001) The role of sediments microorganism in the productivity, conservation and rehabilitation of the mangrove ecosystems: an overview. Biol Fertil Soils 33:265278

24. Hong P, Wu X, Shu Y et al (2019) Denitrification characterization of dissolved oxygen microprofiles in lake surface sediment through analyzing abundance, expression, community composition and enzymatic activities of denitrifier functional genes. AMB Expr 9:129

25. Ikeda AC, Bassani LL, Adamoski D, Stringari D, Kava-Cordeiro V, Glienke C, Steffens MBR, Hungria M, Galli-Terasawa LV (2013) Morphological and genetic characterization of endophytic bacteria isolated from roots of different maize genotypes. Microb Ecol 65:154-160

26. Jenkins BD. Zehr JP (2008) Molecular approaches to the nitrogen cycle. In: Carpenter EJ, editor; Bronk DA, Mulholland MR, Capone D (eds) Nitrogen in the Marine Environment. Elsevier, Amsterdam, pp 1303-1344

27. Kaye JZ, Sylvan JB, Edwards KJ, Baross JA (2011) Halomonas and Marinobacter ecotypes from hydrothermal vent, subseafloor and deep-sea environments. FEMS Microbiol Ecol. Jan;75(1):123-33. 
doi: 10.1111/j.1574-6941.2010.00984.x. Epub 2010 Nov 9. PMID: 21062326

28. Labbé N, Parent S, Villemur R (2004) Nitratireductor aquibiodomus gen. nov., sp. nov., a novel alphaproteobacterium from the marine denitrification system of the Montreal Biodome (Canada). Int $J$ Syst Evol Microbiol 54:269-273. 10.1099/ijs.0.02793-0

29. Lee JA, Francis CA (2017) Spatiotemporal Characterization of San Francisco Bay Denitrifying Communities: a Comparison of nirk and nirS Diversity and Abundance. Microb Ecol 73:271-284

30. .Liu JY, Peng MJ, Li YG (2012) Phylogenetic diversity of nitrogen-fixing bacteria and the nifH gene from mangrove rhizosphere soil. Can J Microbiol 58:531-539. 10.1139/w2012-016Microbiol. 54: 1185-1190 10.1099/ijs.0.028170

31. Li R, Wu S, Chai M, Xie S (2020) Denitrifier communities differ in mangrove wetlands across China, Marine Pollution Bulletin, Volume 155, 2020, 111160, ISSN 0025-326X, https://doi.org/10.1016/j.marpolbul.2020.111160

32. Lovell CR, Davis DA (2012) Specificity of salt marsh diazotrophs for vegetation zones and plant hosts: results from a North American marsh. Front Microbiol 3:84

33. Pereira e Silva MC, Schloter-Hai B, Schloter M, van Elsas JD, Salles JF (2013) Temporal Dynamics of Abundance and Composition of Nitrogen-Fixing Communities across Agricultural Soils. PLoS ONE 8(9):e74500. doi:10.1371/journal.pone.0074500

34. Poly F, Monrozier LJ, Bally R (2001) Improvement in the RFLP procedure for studying the diversity of nifH genes in communities of nitrogen fixers in soil. Res Microbiol 152:95-103

35. Purvaja R, Ramesh R, Ray AK, Rixen T (2008) Nitrogen cycling: A review of the processes, transformations and fluxes in coastal ecosystems. Curr Sci 94:1419-1438

36. Qaisrani MM, Zaheer A, Mirza MS, Naqqash T, Qaisrani TB, Hanif MK, Rasool G, Malik KA, Ullah S, Jamal MS, Mirza Z, Karim S, Rasool M (2019) A comparative study of bacterial diversity based on culturable and culture-independent techniques in the rhizosphere of maize (Zea mays L.). Saudi J Biol Sci Nov 26(7):1344-1351 doi: 10.1016/j.sjbs.2019.03.010. Epub 2019 Apr 1. PMID: 31762594; PMCID: PMC6864194

37. Raju K, Sekar J, Vaiyapuri Ramalingam P (2016) Salinicola rhizosphaerae sp. nov., isolated from the rhizosphere of the mangrove Avicennia marina L. Int J Syst Evol Microbiol 66(2):1074-1079. doi:10.1099/ijsem.0.000837

38. Rameshkumar N, Krishnan R, Lang E, Matsumura Y, Sawabe T (2014) Zunongwangia mangrovi sp. nov., isolated from mangrove (Avicennia marina) rhizosphere, and emended description of the genus Zunongwangia. Int J Syst Evol Microbiol 64:545-550

39. Rameshkumar N, Lang E, Nair S (2010) Mangrovibacter plantisponsor gen. nov., sp. nov., a nitrogenfixing bacterium isolated from a mangrove-associated wild rice (Porteresia coarctata Tateoka). Int J Syst Evol Microbiol 60:179-186

40. Rastogi G, Tech JJ, Coaker GL, Leveau JHJ (2010) A PCR-based toolbox for the culture-independent quantification of total bacterial abundances in plant environments. J Microbiol Methods 83:127-132 
41. Ren M, Zhang Z, Wang X, Zhou Z, Chen D, Zeng H, Zhao S, Chen L, Hu Y, Zhang C, Liang Y, She Q, Zhang Y, Peng N (2018) Diversity and Contributions to Nitrogen Cycling and Carbon Fixation of Soil Salinity Shaped Microbial Communities in Tarim Basin. Front Microbiol Mar 9:9:431. doi:10.3389/fmicb.2018.00431. PMID: 29593680; PMCID: PMC5855357

42. Shivaji S, Chaturvedi P, Suresh K, Reddy GS, Dutt CB, Wainwright M, Narlikar JV, Bhargava PM (2006) Bacillus aeriussp. nov.,Bacillus aerophilussp. nov.,Bacillus stratosphericussp. nov. And Bacillus altitudinis sp. nov., isolated from cryogenic tubes used for collecting air samples from high altitudes. Int J Syst Evol Microbiol 56:1465-1473

43. Vieira SilveiraCB, Cardoso RP, Paranhos AM, Albano R, \&Martins RM,O.B (2011) Influence of Salinity on Bacterioplankton Communities from the Brazilian Rain Forest to the Coastal Atlantic Ocean. PLoS One 6:1-9

44. Tamura D, Peterson N, Stecher G, Nei M, Kumar S (2011) MEGA5: Molecular Evolutionary Genetics Analysis Using Maximum Likelihood, Evolutionary Distance, and Maximum Parsimony Methods. Mol Biol Evol 28(10):2731-2739

45. Vazquez P, Holguin G, Puente M, Lopez-Cortes A, Bashan Y (2000) Phosphate-solubilizing microorganisms associated with the rhizosphere of mangroves in a semiarid coastal lagoon. Biol Fertil Soils 30:460-468. doi:10.1007/s003740050024

46. Viswanath G, Jegan S, Baskaran V, Kathiravan R, Prabavathy VR (2015) Diversity and N-acylhomoserine lactone production by Gammaproteobacteria associated with Avicennia marina rhizosphere of South Indian mangroves. Syst Appl Microbiol 38:340-345

47. Wu P, Xiong X, Xu Z, Lu C, Cheng H, Lyu X et al (2016) Bacterial communities in the rhizospheres of three mangrove tree species from Beilun Estuary, China. PLOS ONE 11:e0164082. doi:10.1371/journal.pone.0164082

48. Xie H, Hong Y, Liu H, Jiao L, Wu J et al (2020) Spatio-temporal shifts in community structure and activity of nirS-type denitrifiers in the sediment cores of Pearl River Estuary. PLOS ONE 15(4):e0231271

49. Yoshida M, Ishii S, Fujii D, Otsuka S, Senoo K (2012) Identification of active denitrifiers in rice paddy soil by DNA- and RNA-based analyses. Microbes Environ 27:456-461

50. Yousuf B, Kumar R, Mishra A, Jha B (2014) Differential distribution and abundance of diazotrophic bacterial communities across different soil niches using a gene-targeted clone library approach. FEMS Microbiol Lett 360:117-125. doi:10.1111/1574-6968.12593

51. Zhang Q, Peng J, Chen Q, Yang X, Hong Y, Su J (2013) Abundance and composition of denitrifiers in response to Spartina alterniflora invasion in estuarine sediment. Can J Microbiol. Dec;59 (12):825 36. doi: 10.1139/cjm-2013-0516. PMID: 24313455

52. Zhang HS, Guo B, Sun J, Zhang M, Cheng Q, Li Q, Hong X, Huang (2015) Mangrovibacter yixingensis sp. nov., isolated from farmland soil Int. J Syst Evol Microbiol 65:2447-2452

53. Zhang Y, Dong J, Yang Z, Zhang S, Wang Y (2008) Phylogenetic diversity of nitrogen-fixing bacteria in mangrove sediments assessed by PCR-denaturing gradient gel electrophoresis. Arch Microbiol 
190:19-28

54. Zhang Y, Yang Q, Ling J, Van Nostrand JD, Shi Z, Zhou J, Dong J (2017) Diversity and Structure of Diazotrophic Communities in Mangrove Rhizosphere, Revealed by High-Throughput Sequencing. Front Microbiol 8:2032. doi:10.3389/fmicb.2017.02032

55. Zheng YL, Hou LJ, Liu M, Gao J, Yin GY, Li XF et al (2013) Diversity, Abundance, and Distribution of nirS-Harboring Denitrifiers in Intertidal Sediments of the Yangtze Estuary. Microbial Ecology. 2015; 70: $30-40$

56. Zhou H, Dang HY, Klotz MG (2016) Environmental conditions outweigh geographical contiguity in determining the similarity of nifHharboring microbial communities in sediments of two disconnected marginal seas. Front Microbiol 7:1111. doi:10.3389/fmicb.2016.01111

\section{Tables}

Tables 1-2 and Tables S1-S3 were not provided with this version of the manuscript.

Figures
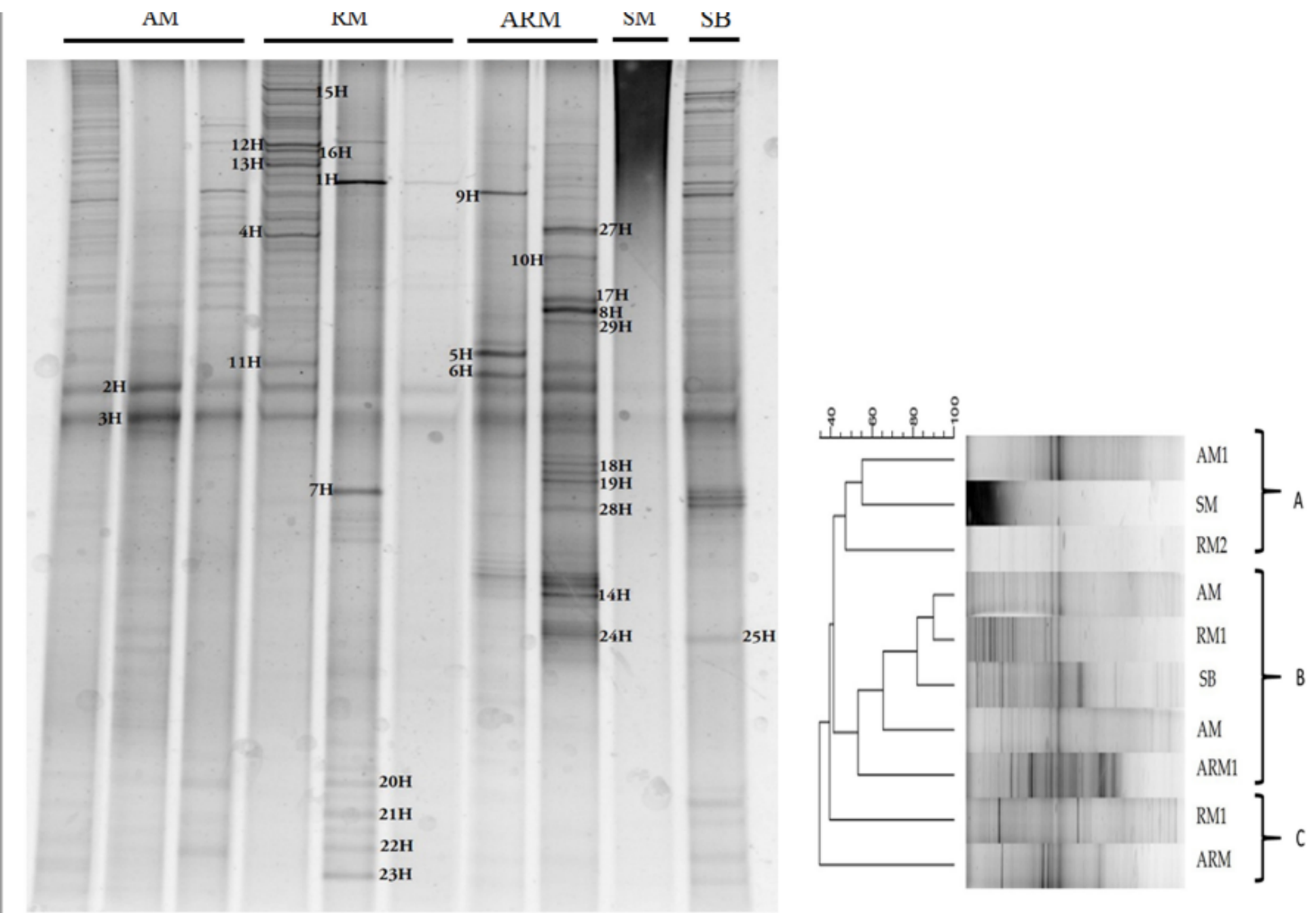
Figure 1

a. DGGE analysis of nifH gene. b. Cluster analysis of DGGE profile nitrogen fixers by UPGMA algorithm
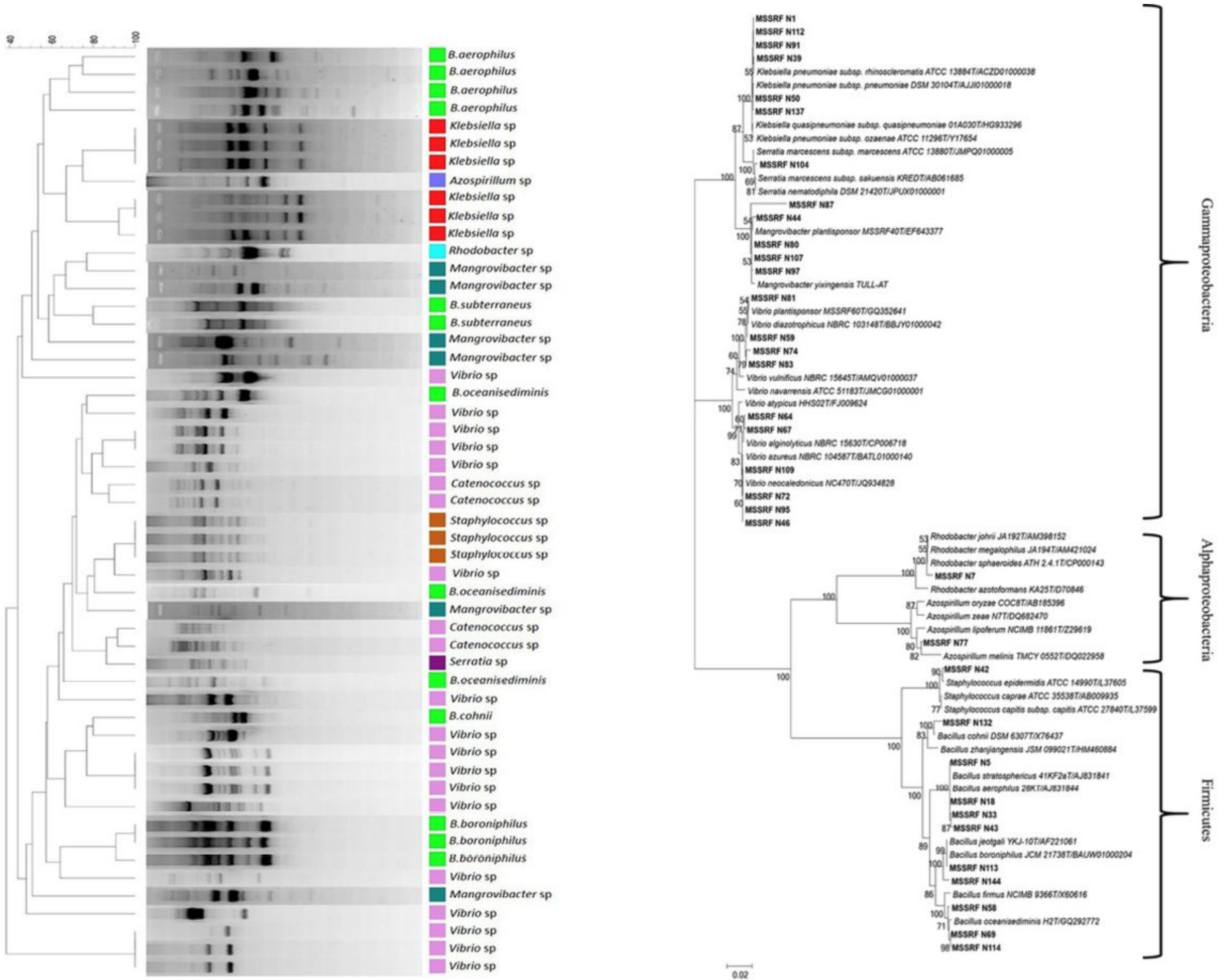

Figure 2

a. Cluster analysis of Nitrogen fixers based on Dice coefficient and dendrogram construction by UPGMA algorithm. b. Neighbor joining analysis of culturable Nitrogen fixers based on 16S rDNA analysis. A bootstrap value of 1000 replicates have been carried out for analysis 


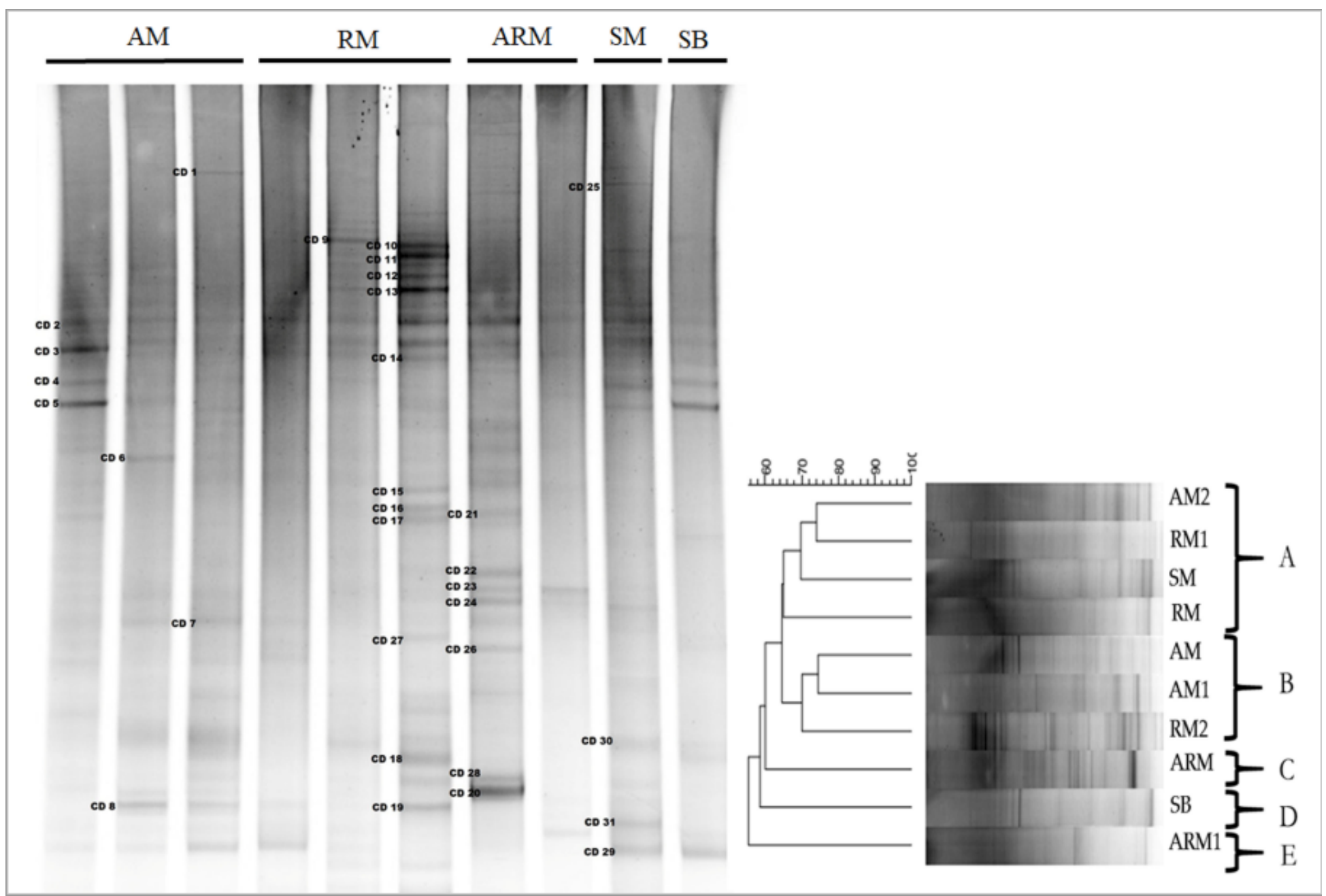

Figure 3

a. DGGE analysis of nirS gene. b. Cluster analysis of DGGE profile cdnirS community by UPGMA algorithm 


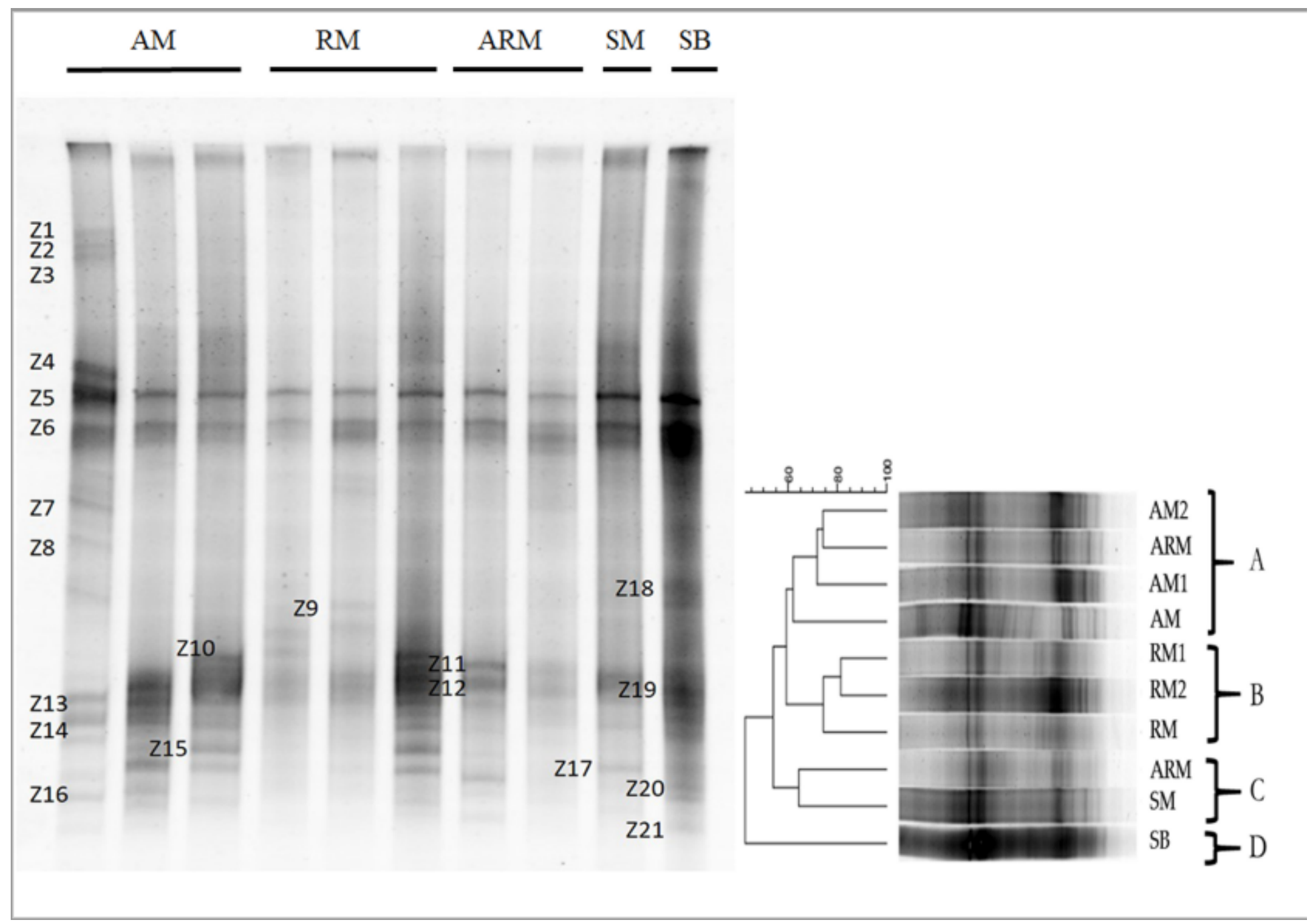

Figure 4

a. DGGE analysis of nosZ gene. b. Cluster analysis of DGGE profile nosZ community by UPGMA algorithm 


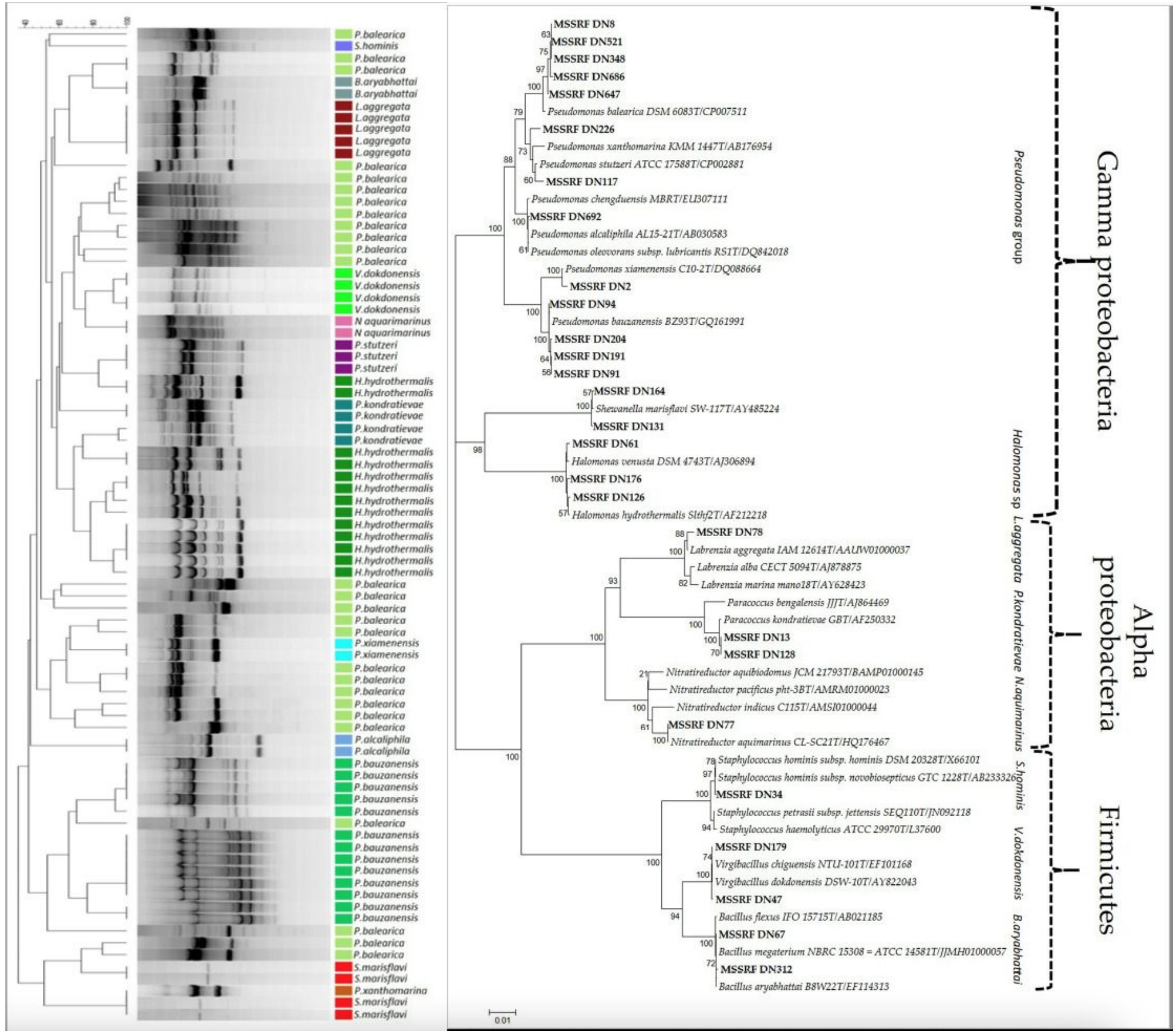

Figure 5

a. BOX-PCR Cluster analysis of positive isolates of denitrifiers based on Dice coefficient and dendrogram construction by UPGMA algorithm. b. Neighbor joining analysis of culturable denitrifiers based on $16 \mathrm{~S}$ rDNA analysis. A bootstrap value of 1000 replicates have been carried out for analysis

\section{Supplementary Files}

This is a list of supplementary files associated with this preprint. Click to download.

- FigS1.pdf

- FigS2.pdf 
- FigS3.pdf

- FigS4AFigS4b.pdf 